\title{
QUANTUM CHEMISTRY MOLECULAR MODELING FOR RADIO- FREQUENCY AND MICROWAVE- FREQUENCY THERMO-UPCONVERSION HEATING OF TRANSITION METAL OXIDES OF NiO AND Fe2O3
}

\author{
Shozo Yanagida ${ }^{1}$, and Takeko Matsumura ${ }^{2}$

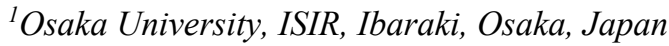 \\ ${ }^{2}$ Minerva Light Laboratory, Kyoto, Japan \\ yanangida@mls.eng.osaka-u.ac.jp
}

Keywords: DFT, molecular modeling, Spartan, IR/FIR, thermo-upconversion, dielectric heating

\section{Introduction}

Most solid-state inorganic materials heat up by microwave (MW) induced conductivity and dielectric loss heating, and the MW heating power to transition metal oxides, which have unpaired electron (spin), was considered to be proportional to dielectric heating relating to magnetic loss factor relating to spin in transition metal oxides. We know, however, that, nickel oxide ( $\mathrm{Ni}(\mathrm{II}) \mathrm{O}, 25 \mathrm{gr})$ ) having 2 unpaired electron, heat up to $1,300^{\circ} \mathrm{C}$ in 6 min under $1 \mathrm{~kW}-\mathrm{MW}$ irradiance, and that. ferric oxide ( $\left.\mathrm{Fe}(\mathrm{III})_{2} \mathrm{O}_{3}, 25 \mathrm{gr}\right)$ having 10 unpaired electron, up to only $88^{\circ} \mathrm{C}$ in $30 \mathrm{~min}$ under the same $1 \mathrm{~kW}-\mathrm{MW}$ irradiance. ${ }^{1)}$ The big difference in MW heating is now attempted to rationalize on the basis of density functional theory-based molecular modeling (DFT/MM). Recently, we reported that DFT/MM verifies that water aggregates undergo absorption and emission in radio-frequency wave, MW and FIR region, resulting in thermal absorption and dissipation, i.e., heat of IR radication. We proposed that MW and radio frequency heating of water should instantly proceed thermo-upconversion mechanism under MW energy irradicance. ${ }^{2)}$

For density functional theory-based molecular modeling (DFT/MM, B3LYP, 6$\left.31 \mathrm{G}^{*}\right) \mathrm{DFT} / \mathrm{MM}$, we take into account that both nickel and ferrite oxides should be composed of covalent-bonding metal oxides of respective $\mathrm{Ni}(\mathrm{II}) \mathrm{O}$ or $\mathrm{Fe}(\mathrm{III})_{2} \mathrm{O}_{3}$, and their van der Waals $(\mathrm{vdW})$ aggregates of $[\mathrm{Ni}(\mathrm{II}) \mathrm{O}]_{\mathrm{n}}(\mathrm{n}=2 \sim 4)$ and $\left[\mathrm{Fe}(\mathrm{III})_{2} \mathrm{O}_{3}\right]_{\mathrm{n}}(\mathrm{n}=2 \sim 4)$. We obtain their equilibrium three-dimensional molecular-aggregate structures, showing them with electron density in Table 1 and 2. Electron energy structures result in giving infrared (IR), far infrared (FIR), MW, and, radio-frequency wave- energy absorption spectra. It should be noted that stretching and bending and concerted back and forth movement between composed elements can be visualized for molecular aggregates of [Ni(II)O $]_{n}(n=2 \sim 4)$ and $\left[\mathrm{Fe}(\mathrm{III})_{2} \mathrm{O}_{3}\right]_{\mathrm{n}}(\mathrm{n}=2 \sim 4)$ by clicking strong absorption peaks especially in $500 \sim 0 \mathrm{~cm}^{-1}$ region. It is very interesting to recognize that radio frequency wave, MW and FIR absorption induce back and forth movement of atoms in vdW aggregates and thermo-upconversion starts very quickly to FIR and IR absorption and emission. IR emission is heating.

DFT/MM of molecular vdW aggregates gives heat of formation ( $\square \mathrm{E}$ ), the energy level of the lowest unoccupied molecular orbital (ELUMO) and energy level of the highest occupied molecular orbital (EHOMO), dipole, and electron transfer gap ( $\square \mathrm{Et}$ ) that can be calculated from ELUMO (0) and ELUMO (+1). The bandgap will be a measure of conductivity. They are all summarized with IR and FIR absorption peaks with high intensity in Table 1 and 2. Clicking intense IR and FIR absorption peaks makes us understand that thermoupconversion starts at concerted back and forth movement of atoms in molecular aggregates. 


\section{DFT/MM for quick MW heating of nickel oxides}

Table 10 DFT/MM for IR and FIR absorption spectrum analysis of Ni(II) oxides

\begin{tabular}{|c|c|c|c|c|c|c|}
\hline $\begin{array}{l}\text { Nickel(II) } \\
\text { oxide }\end{array}$ & $\begin{array}{l}\text { Equilibrium } \\
\text { geometry with } \\
\text { density }\end{array}$ & $\begin{array}{l}\text { Heat of } \\
\text { formation } \\
\text { (E/au) }\end{array}$ & $\begin{array}{l}\text { Dipole } \\
\text { (debye) }\end{array}$ & $\begin{array}{c}\text { Conductivity } \\
\text { measure: } \\
\begin{array}{c}\Delta E=\alpha L U M O\{+1\} \\
-\alpha L U M O^{* *}\end{array}\end{array}$ & $\begin{array}{l}\text { FIR region } \\
\left(0 \sim 500 \mathrm{~cm}^{-1}\right) \\
\mathrm{cm}^{-1} \text { (intensity) }\end{array}$ & $\begin{array}{c}\text { IR region } \\
\left(3500 \sim 500 \mathrm{~cm}^{-1}\right) \\
\mathrm{cm}^{-1} \text { (intensity) }\end{array}$ \\
\hline $\begin{array}{c}\mathrm{NiO} \\
\text { Unpaired } \\
\text { electron } 2\end{array}$ & & -1583.20835 & 2.01 & 0.23 & $379(33.57$ & - \\
\hline $\begin{array}{c}\mathrm{Ni}_{2} \mathrm{O}_{2} \\
\text { Unpaired } \\
\text { electron } 4\end{array}$ & & -0.24919 & 0 & 1.30 & $\begin{array}{l}198(58.1) \\
472(194)\end{array}$ & 639(99.3) \\
\hline $\begin{array}{c}\mathrm{Ni}_{4} \mathrm{O}_{4} \\
\text { Unpaired } \\
\text { electron } 8\end{array}$ & & -0.71603 & 0.01 & 1.51 & $\begin{array}{c}172(0.2), 178(2.97) \\
183(3.02), 184(2.49) \\
430(1.89), 455(164) \\
456(170), 461(167)\end{array}$ & $\begin{array}{l}535(58.4) \\
539(62.1)\end{array}$ \\
\hline $\begin{array}{c}\text { Single point } \\
\text { vdW dimer } \\
*\left(\mathrm{Ni}_{4} \mathrm{O}_{4}\right)_{2} \\
\text { Unpaired } \\
\text { electron } 16\end{array}$ & If & $-1.3948 *$ & 0 & 0.42 & $\begin{array}{c}133(4.35), 169(3.11) \\
169(3.12), 170(4.6) \\
264(0.06), 428(0.62)\end{array}$ & $\begin{array}{c}518(477), 531(192) \\
536(398), 536(398) \\
580(4.87)\end{array}$ \\
\hline
\end{tabular}
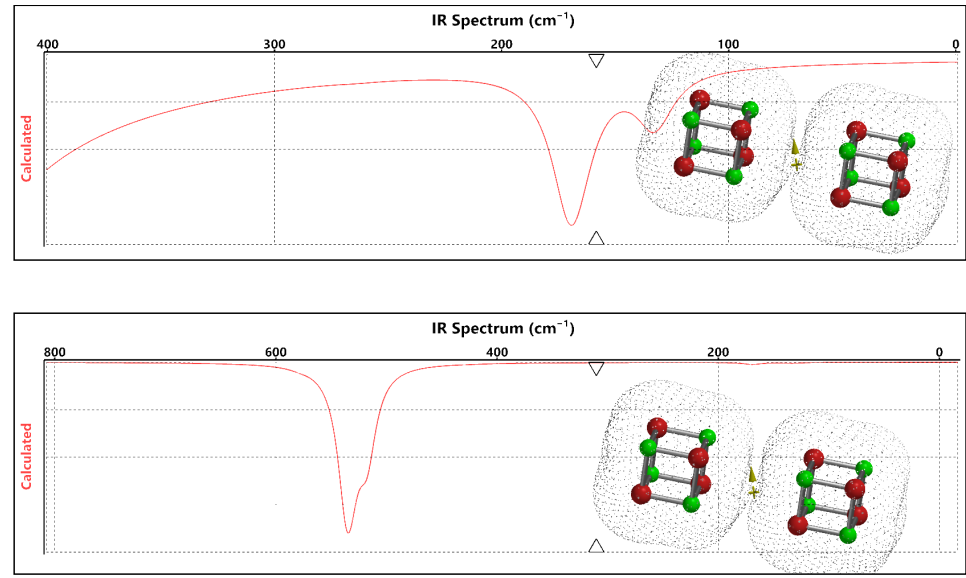

Fig. 1. DFT/MM-determined FIR and IR absorption spectra of singlepoint vdW dimer of $*\left[\left(\mathrm{Ni}_{4} \mathrm{O}_{4}\right)_{2}\right]_{2}$

DFT/MM of nickel oxides gives a dimer of $\mathrm{Ni}_{2} \mathrm{O}_{2}$, a tetramer $\left(\mathrm{Ni}_{4} \mathrm{O}_{4}\right)$ and vdW aggregate of the tetramer (Table 1) when unpaired electron 2 for each nickel (II) atom is taken into consideration. Two of them are shown covalent bonding structures with surface electron density (dots style) and are thermally stable as proved by negative heat of formation. All of them have a small dipole. Previously we reported that conductivity of molecular aggregates should be evaluated by bandgap between electron running states (biased state) of molecules and aggregates. ${ }^{3)}$ At electron running states of nickel oxides, $\alpha$ LUMO (0) will become singly occupied molecular orbital (SOMO) and $\alpha \mathrm{LUMO}(+1)$ will become $\alpha \mathrm{LUMO}(0)$ of the electron-running-state nickel oxides (" $\alpha$ " stands for alpha spin). Conductivity measure of $\Delta \mathrm{E}=\alpha \mathrm{LUMO}\{+1\}-\alpha \mathrm{LUMO}$ verifies that they have semi-conductivity, predicting that conductivity may contribute to MW heating at elevated temperature. 
The covalent-bonding $\mathrm{Ni}(\mathrm{II}) \mathrm{O}$ dimer, $\mathrm{Ni}_{2} \mathrm{O}_{2}$, the covalent-bonding $\mathrm{Ni}(\mathrm{II}) \mathrm{O}$ tetramer, $\mathrm{Ni}_{4} \mathrm{O}_{4}$, and the vdW dimer of $\left(\mathrm{Ni}_{4} \mathrm{O}_{4}\right)_{2}$ are molecular modeled to know if thermo-upconversion mechanism is operating in the MW heating of nickel oxides. The single point energy structure of $\left(\mathrm{Ni}_{4} \mathrm{O}_{4}\right)_{2}$ is obtained and analyzed although heat of formation $\mathrm{f}$ is positive. Because the equilibrium geometry could not be molecular modeled contrast to the case of $\mathrm{Fe}(\mathrm{III})_{2} \mathrm{O}_{3}$ (see Table 2).

Table 1 shows that all of $\mathrm{Ni}$ (II)O aggregates have absorption with high intensity in 500 0 $\mathrm{cm}^{-1}$ region including MW and radio-frequency wave. In addition, the stronger absorption expands to the IR absorption and dissipation region. Typical FIR and IR absorption spectra shown in Fig. 1 verifies and predicts the thermo-upconversion occurs effectively during MW heating of nickel oxides.

\section{DFT/MM for MW heating of ferric oxides}

DFT/MM is extended to ferric oxides by taking into account of unpaired electron 5 for each $\mathrm{Fe}(\mathrm{III})$ atom . The equilibrium geometry of covalent-bonding of $\mathrm{Fe}_{2} \mathrm{O}_{3}$ and single pint energy structure of vdW aggregates of $\left[\mathrm{Fe}(\mathrm{III})_{2} \mathrm{O}_{3}\right]_{2}$ are successfully modeled and their heat of formation, dipole and conductivity measure $\Delta \mathrm{E}=\alpha \mathrm{LUMO}\{+1\}-\alpha \mathrm{LUMO}$ are summarized in Table 2. They have no dipole, but have semi-conductivity comparable to the nickel oxides. Interestingly, the equilibrium geometry structure $\mathrm{Fe}_{2} \mathrm{O}_{3}$ and the single pint energy structure of vdW aggregates have no absorption in IR region of more than $500 \mathrm{~cm}^{-1}$. These calculation results well verify slow MW heating of ferrite as reported. ${ }^{1)}$

Table 20 DFT/MM for IR and FIR absorption spectrum analysis of $\mathrm{Fe}(\mathrm{III})_{2} \mathrm{O}_{3}$

\begin{tabular}{|c|c|c|c|c|c|c|}
\hline $\mathrm{Fe}(\mathrm{III})_{2} \mathrm{O}_{3}$ & $\begin{array}{l}\text { Equilibrium } \\
\text { geometry with } \\
\text { density }\end{array}$ & $\begin{array}{l}\text { Heat of } \\
\text { formation } \\
\text { (E/au) }\end{array}$ & $\begin{array}{l}\text { Dipole } \\
\text { (debye) }\end{array}$ & $\begin{array}{c}\text { Conductivity } \\
\text { measure: } \\
\Delta E=\alpha L U M O\{+1\}- \\
\alpha L U M O * *\end{array}$ & $\begin{array}{l}\text { FIR region } \\
\left(0 \sim 500 \mathrm{~cm}^{-1}\right) \\
\mathrm{cm}^{-1} \text { (intensity) }\end{array}$ & $\begin{array}{c}\text { IR region } \\
\left(3500 \sim 500 \mathrm{~cm}^{-1}\right) \\
\mathrm{cm}^{-1} \text { (intensity) }\end{array}$ \\
\hline $\begin{array}{c}\mathrm{Fe}(\mathrm{III})_{2} \mathrm{O}_{3} \\
\text { Unpaired electron } \\
10\end{array}$ & & -2752.8048 & 0 & 1.25 & $\begin{array}{l}102(2.65) \\
117(2.78) \\
387(81.8)\end{array}$ & $549(0.09)$ \\
\hline $\begin{array}{c}\text { *vdW dimer } \\
{\left[\mathrm{Fe}(\mathrm{III})_{2} \mathrm{O}_{3}\right]_{2}} \\
\text { Unpaired electron } \\
20\end{array}$ & & 0.24497 & 0 & 0.26 & $\begin{array}{c}118(122) .155(17.1) \\
253(31.5), 279(24.7) \\
302(12.7), 356(10.84)\end{array}$ & No absorption \\
\hline $\begin{array}{c}\text { vdW dimer } \\
{\left[\mathrm{Fe}(\mathrm{III})_{2} \mathrm{O}_{3}\right]_{2}} \\
\text { Unpaired electron } \\
20\end{array}$ & & -0.2593 & 0 & 0.79 & $\begin{array}{c}62(9.72), 175(39.9) \\
208(29.1), 231(98.2) \\
301(0.17), 393(0.21)\end{array}$ & $\begin{array}{l}535(30.8), 585(166) \\
644(426), 722(606)\end{array}$ \\
\hline $\begin{array}{c}\mathrm{Fe}(\mathrm{III})_{4} \mathrm{O}_{6} \\
\text { Unpaired electron } \\
20\end{array}$ & & -0.25926 & 0.05 & 0.79 & $\begin{array}{c}58(9.5), 174(40.0) \\
208(29.7), 231(98.2) \\
301(0.17), 393(0.21)\end{array}$ & $\begin{array}{c}534(31.1), 584(166) \\
644(426), 666(7.5) \\
722(607)\end{array}$ \\
\hline $\begin{array}{c}\text { vdW dimer } \\
{\left[\mathrm{Fe}(\mathrm{III})_{4} \mathrm{O}_{6}\right]_{2}} \\
\text { Unpaired electron } \\
20\end{array}$ & & -0.7066 & 0 & 0.35 & $\begin{array}{c}54(0.02), 61(3.3), \\
72(7.4), 86(7.1) \\
139(0.53), 142(49.2) \\
205(15.4), \\
217(24.3)\end{array}$ & $\begin{array}{l}534(31.1), 584(166) \\
644(426), 666(426) \\
653(177), 658(374)\end{array}$ \\
\hline
\end{tabular}

* Single point calculation, ** “ $\alpha$ ” stands for alpha spin. 
Interestingly, DFT/MM for an equilibrium geometry of a vdW dimer of [ $\left.\mathrm{Fe}(\mathrm{III})_{2} \mathrm{O}_{3}\right]_{2}$ leads to covalent bonding $\mathrm{Fe}(\mathrm{III})_{4} \mathrm{O}_{6}$. The vdW dimer $\left[\mathrm{Fe}(\mathrm{III})_{2} \mathrm{O}_{3}\right]_{2}$ is structurally identical with the covalent bonding $\mathrm{Fe}(\mathrm{III})_{4} \mathrm{O}_{6}$ as shown in Table 2. Further DFT/MM is successful for obtaining an equilibrium geometry for the vdW dimer of $\left[\mathrm{Fe}(\mathrm{III})_{4} \mathrm{O}_{6}\right]_{2}$. They all have negative heat of formation and then the structure ae thermally stabilized.
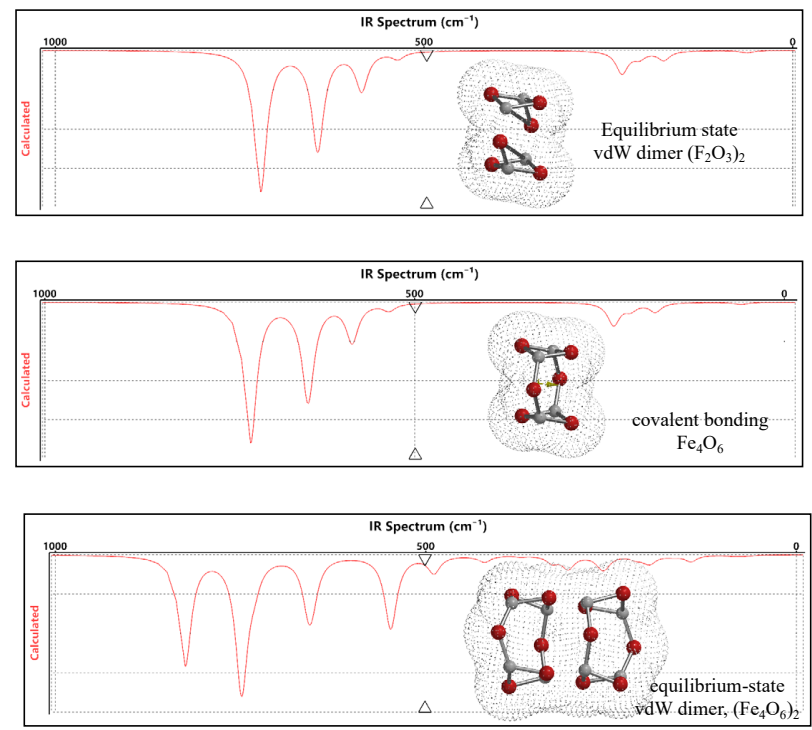

Fig. 2. DFT/MM-determined FIR and IR absorption spectra of equilibriumstate vdW dimer $\left(\mathrm{F}_{2} \mathrm{O}_{3}\right)_{2}, \mathrm{Fe}_{4} \mathrm{O}_{6}$ and equilibrium-state vdW dimer, $\left(\mathrm{Fe}_{4} \mathrm{O}_{6}\right)_{2}$

Fig. 2 shows IR and FIR absorption spectra of the equilibrium-state vdW dimer of $\left[\mathrm{Fe}(\mathrm{III})_{2} \mathrm{O}_{3}\right]_{2}$, covalent bonding $\mathrm{Fe}(\mathrm{III})_{4} \mathrm{O}_{6}$ and its equilibrium-state vdW dimer, $\left[\mathrm{Fe}(\mathrm{III})_{4} \mathrm{O}_{6}\right]_{2}$. Contrary to the case of $\mathrm{Fe}(\mathrm{III})_{2} \mathrm{O}_{3}$, Covalently bonding $\mathrm{Fe}(\mathrm{III})_{4} \mathrm{O}_{6}$ structures are verified to undergoes thermo-upconversion. On careful examination, Koleini and Barani reported that $\mathrm{Fe}_{2} \mathrm{O}_{3}$ heats up to $1000{ }^{\circ} \mathrm{C}$ at 6 -min interval. ${ }^{4}$ Then we conclude that ferrite heat up accompanying structural change under MW irradiance.

\section{References}

1. S.L. McGill and J.W. Walkiewicz, J. Microwave Power Electromag. Energy, Symp. Summ., 1987, 175.

2. S. Yanagida and T. Matsumura, AMPERE Newsletter, 95, 27, 2018

3. S. Yanagida, et al, J. Electrochem. Soc., 162 (10) E263-E270 (2015)

4. S.M.J. Koleini and K. Barani, "Microwave Heating Applications in Mineral Processing" (http://dx.doi.org/10.5772/45750) 